\title{
LETTERS
}

Send your letters to the editor, British Dental Journal, 64 Wimpole Street, London W1G 8YS or byemail tobdj@bda.org

Priority will be given to letters less than 500 words long. Letters should be typed. Authors must sign the letter, which may be edited for reasons of space

\section{Classification approach}

Sir, we read with interest the paper on 'Phantom bite revisited.' ${ }^{1}$ The authors have not used a recognised diagnostic system and refer to 'mono-symptomatic hypochondriacal psychosis' which is no longer used in the psychiatric literature.

All the cases described were preoccupied with an imagined defect or had a minor physical anomaly and their concern was regarded as markedly excessive. They were clearly significantly distressed and handicapped. These are precisely the diagnostic criteria for body dysmorphic disorder ${ }^{2}$ (BDD). If the beliefs are held with no insight, then an additional diagnosis can be made of a delusional disorder. In ICD-10, the term BDD or the older term 'dysmorphophobia' is not separately classified and is subsumed under hypochondriacal disorder. $^{3}$

If however the beliefs are held with no insight, then an alternative diagnosis of 'Other persistent delusional disorder' is made. The preoccupation with a dental occlusion needs to be seen in the wider context of preoccupation in other patients with perceived defects such as slight flaws on the face, body features being too small or too big, hair thinning, wrinkles, spots, scars, asymmetry or lack of proportion. There is frequent comorbidity in BDD with depression, a significant risk of suicide ${ }^{4,5}$ and dissatisfaction with cosmetic surgery. 6,7

The authors make a number of recommendations for treatment with pimozide (an anti-psychotic drug) which is not evidence based. There have been two randomised controlled trials of serotonin reuptake inhibitor with BDD. 8,9

In short, the evidence favours the use of an SSRI in high doses for at least 12 weeks even in delusional patients. Furthermore Phillips ${ }^{10}$ has conducted a randomised controlled trial of pimozide augmentation of an SSRI in BDD or its delusional variant and found it to be no more effective than placebo. Phillips ${ }^{11}$ has also conducted a retrospective survey in BDD in which only $3 \%$ of 83 trials of an anti-psychotic (including pimozide) were of any benefit in BDD.

The authors also refer to building adaptive coping skills and overall functioning. We would agree, but this needs to be in the context of a testable theory and identifying the factors that maintain the preoccupation.

This can be done through a cognitive behavioural model ${ }^{12}$ for which there is an evidence base with two RCTs. ${ }^{13,14}$ The key issue in engagement of a patient with BDD or hypochondriasis is helping the patient to have a good understanding of what the problem is (rather what it is not) and validating the patient's experience. The patient is trying too hard to solve the wrong problem and their solutions have now become their problem.

Therapy therefore progresses in trying to identify the factors that maintain the preoccupation and distress. These might include selective attention and increased awareness of small occlusal discrepancies; ruminating about the sensation; the excessive monitoring of the sensation by checking and clenching of teeth and bruxism; treatment seeking and further pain leading to increased awareness in a vicious circle.

This in turn would lead to avoidance of normal activities. All of the maintaining factors have to be dismantled for the patient to become functional.

\section{Veale, London}

\section{H. Chapman, Horsham}

1 Jagger RG, Korszun A. Phantom bite revisited. Br Dent J 2004; 197(5):241-243.

2 American Psychiatric Association. Diagnostic and statistical manual of mental disorders. 4th ed. Washington DC: APA, 1994.

3 World Health Organisation. The ICD-10. Classification of mental and behavioural disorders. Geneva: World Health Organisation, 1992.

4 Phillips KA. Body dysmorphic disorder: the distress of imagined ugliness. Am J Psychiatry 1991; 48(9):1138-1149.

5 Veale D, Boocock A, Gournay K, Dryden W, Shah F. Willson R et al. Body dysmorphic disorder. A survey of fifty cases. Br J Psychiatry 1996; 169(2):196-201.

6 Veale D. Outcome of cosmetic surgery and 'DIY' surgery in patients with body dysmorphic disorder. Psychiatr Bull 2000; 24:218-221.

7 Phillips KA, McElroy SL, Keck PE, Jr., Pope HG, Jr., Hudson Jl. Body dysmorphic disorder: 30 cases of imagined ugliness. Am J Psychiatry 1993; 150(2):302-308
8 Phillips KA, Albertini RS, Rasmussen SA. A randomized placebo-controlled trial offluoxetine in body dysmorphic disorder. Arch Gen Psychiatry 2002; 59:381-388.

9 Hollander E, Allen A, Kwon J, Aronowitz B, Schmeidler J Wong $C$ et al. Clomipramine vs desipramine crossover trial in body dysmorphic disorder: selective efficacy of a serotonin reuptake inhibitor in imagined ugliness. Arch Gen Psychiatry 1999; 56(11): $1033-1042$.

10 Phillips KA. A placebo-controlled study of pimozide augmentation of fluoxetine in body dysmorphic disorder. Am J Psychiatry. In press.

11 Phillips KA. Pharmacologic treatment of body dysmorphic disorder. Psychopharmacol Bull 1996; 32(4):597-605.

12 Veale D. Advances in a cognitive behavioural model of body dysmorphic disorder. Body Image 2004; 1:113125.

13 Veale D, Gournay K, Dryden W, Boocock A, Shah F, Willson R etal. Body Dysmorphic Disorder: A Cognitive Behavioural Model and Pilot Randomised Controlled Trial. Behav Res Ther 1996 34(9):717-729.

14 Rosen JC, Reiter J, Orosan P. Cognitive-behavioural body image therapy for body dysmorphic disorder. J Consult Clin Psycho/1995; 63:263-269.

One of the authors of the paper, $R G$ Jagger responds: We appreciate the interest in our article and in general agree with the views of Drs Veale and Chapman. However, although it is true that mono-symptomatic hypochondriacal psychosis is not a term currently used in the psychiatric literature, it was the term originally used by Marbach ${ }^{1}$. This original conceptualisation is still widely read and it was this historical term which we were 'revisiting'. There is indeed an overlap between body dysmorphic disorder (BDD) and 'phantom bite', with the shared feature of markedly excessive concern over a minor feature with consequent impairment in important areas of function.

However, an essential requirement for a diagnosis of $B D D$, as classified in DSM$I V 2$, is a preoccupation with appearance and it is important to note that none of the three reported patients had such a preoccupation.

As Drs Veale and Chapman point out, in ICD-10 both BDD and phantom bite fall into the category of 'hypochondriacal disorder' which subsumes a widely heterogeneous group of disorders. However, the point is that both DSM-IV and ICD-10 are over ten years old and more recently there has been a shift away from this categorical approach of classification. 
Systems in which individuals are fitted into subcategories that are separate and mutually exclusive are being replaced by dimensional ones in which symptoms are grouped together within different symptom dimensions that can coexist to different degrees in individual patients ${ }^{3,4}$. But, any further academic discussion here of psychiatric classification is probably not helpful to the busy dental practitioner who is trying to deal with a patient with phantom bite.

Whilst we agree that SSRI's have been used successfully in the treatment of related conditions such as $B D D$, we would not recommend that the general dentist take this approach but, as we emphasised in our paper, patients with phantom bite who do not respond to obvious conservative measures should be referred for psychiatric assessment and specialist management.

This may include CBT, but in practice it is often impossible to persuade patients even to consider this option. Also, as described in Case 2, they may be unwilling to take any medication, despite symptoms of severe major depression with suicidal ideation.

It is encouraging that there is an interest in these difficult to treat conditions. We hope that the major advances that have taken place over the last few years in the understanding of neuropsychiatric disorders will move us away from rigid classification towards a more rational basis for developing treatments ${ }^{5}$.

1. Marbach JJ. Phantom bite. Am J Orthod.1976; 70:190-199

2. American Psychiatric Association. Diagnostic and Statistical Manual of Mental Disorders DSM-IV, Washington D.C. 1994

3. Wickham $\mathrm{H}$, Walsh $\mathrm{C}$, Asherson $\mathrm{P}$, Taylor $\mathrm{C}$ Sigmundson T, Gill M, Owen MJ, McGuffin P, Murray $R$, Sham P. Familiality of symptom dimensions in schizophrenia. Schizophr Res 2001;47:223-232.

4. Korszun A, Moskvina V, Brewster S, Craddock N, Ferrero F, Gill M, Jones IR, Jones LA, Sc Maier W, Mors 0, Owen MJ, Preisig M, Reich T, Rietschel M, Farmer A, McGuffin P. (2004) Familiality of symptom dimensions in depression. Archives of General Psychiatry 61 :468-474

5. Hyman SE, Fenton WS. Medicine: what are the right targets for psychopharmacology? Science 2003; 299:350-351.

doi: 10.1038/sj.bdj.4812012

\section{Life-stages}

Sir, I refer to the article by G Hoad-Reddick in $B D J 2004,197: 9$, which made an interesting change from purely clinical topics. However, for a peer-reviewed journal, I am concerned that too many of the statements in the article appeared to be speculative, while the concluding points seemed particularly contentious.

Although this is an Opinion piece, the paragraphs about life-stages contain a lot of statements without references - when they could have been backed up with evidence or dropped.

This applies, for example, to the statement that problems overseeing preadolescent children's oral hygiene 'may cause stresses to affect the relationship between parent and child'. Do we know?

The suggestion that the Mona Lisa's enigmatic non-smile was caused by her hiding her dental decay seems distinctly out of place in a scientific journal.

If I were to speculate, it might be that her teeth were not unusually decayed, but that her composed features reflect the days before Hello magazine when grinning for portraits was a great deal less fashionable.

The statements that middle-aged women 'may' report tooth decay during pregnancy, and that "possibly during pregnancy women neglect tooth cleansing and are unaware of dental problems until they have time to themselves when children are older' also need some kind of back-up.

Pregnancy can have an effect on gum health, but this is not mentioned. The assertion that these women "may start to question whether their appearance has declined and attend for treatment hoping their looks can be restored' left me dubious. Is there qualitative research to show this?

The final paragraph causes me most concern. How does the author know that 'it seems certain that practitioners who focused their practice in this way would have greater fulfilment in their work and thus would provide maximum benefit to patients'? Just saying it doesn't make it true, never mind the practicalities of delivering counselling within the financial and time constraints of NHS dentistry!

Most worryingly, the final sentence acknowledges that research is needed, but then seems to predetermine what the conclusions will be: 'If appropriate evidence-based research were conducted, the importance of this approach would be recognised'.

The counselling approach could just as easily discredited - the role of independent research is to find out whether it an intervention is beneficial or not, not to prove a point that has already been decided.

\section{Stillman-Lowe}

Twyford Reading

doi: 10.1038/sj.bdj.4812013

The author of the paper chose not to respond to this letter.

We would like to apologise for an omission in the letters page in BDJ 197:12. The letter entitled 'Editorial control' should also have been co-signed by A. Blinkhorn. We apologise for this oversight. 